\title{
Serum Anti-Müllerian Hormone as a Predictor of Polycystic Ovarian Syndrome among Women of Reproductive Age
}

\section{Muhammad Salman Butt \\ University of the Punjab \\ Javeria Saleem \\ University of the Punjab}

Sobia Aiman

Akhtar Saeed Medical and Dental College

Rubeena Zakar

University of the Punjab

Iftikhar Sadique

Akhtar Saeed Medical and Dental College

Florian Fischer ( $\square$ florian.fischer1@charite.de)

Institute of Public Health, Charité - Universitätsmedizin Berlin

\section{Research Article}

Keywords: Anti-Müllerian hormone, PCOS, Rotterdam criteria, hirsutism, reproductive health

Posted Date: February 18th, 2022

DOI: https://doi.org/10.21203/rs.3.rs-1351570/v1

License: (1) This work is licensed under a Creative Commons Attribution 4.0 International License.

Read Full License 


\section{Abstract}

Background: The Polycystic Ovarian Syndrome (PCOS) affects up to a fifth of women of reproductive age and causes anovulatory subfertility. Some studies have recommended that an Anti-Müllerian Hormone (AMH) level greater than $3.8-5 \mathrm{ng} / \mathrm{mL}$ can be used for diagnosing PCOS. Therefore, this study aims to analyze the serum AMH level as a predictor of PCOS among women of reproductive age.

Methods: A total of 51 women of reproductive age, recently diagnosed with PCOS (meeting the Rotterdam criteria), were selected. A cross-sectional study design was used to estimate the AMH levels among PCOS women. Baseline variables, menstrual cycle length, ovarian morphology on the ultrasound, hirsutism, sex hormones, gonadotropin, and serum AMH levels were analyzed during the follicular phase (1-5 days) of the menstrual cycle.

Results: A high serum AMH level $(7.23 \pm 4.67 \mathrm{ng} / \mathrm{ml})$ was recorded with normal sex hormone levels. Women with oligo-/amenorrhea had a significant mean difference for luteinizing hormone $(p=0.02)$ and AMH levels $(p=0.03)$ when compared with women of normal menstrual cycle length. PCOS women with high AMH levels $(\geq 3.9 \mathrm{ng} / \mathrm{ml})$ showed a significant difference in ovarian morphology $(p<0.05)$ when compared with the normal $\mathrm{AMH}$ group.

Conclusions: Serum AMH level can be used as a strong predictor for disturbance in reproductive characteristics such as menstrual cycle disturbance, polycystic ovarian morphology, and clinical signs of hyperandrogenism. An elevated serum AMH level could reflect the certainty of PCOS diagnosis among women of reproductive age with a greater number of PCOS features.

\section{Background}

Polycystic ovarian syndrome (PCOS) is getting one of the most prevalent endocrine abnormalities for women of reproductive age. The prevalence of PCOS varies among ethnic populations and appears to decrease with age. It is estimated that British women aged 20-25 years have a prevalence of 33\% [1]; Finish women aged less than 36 years have a prevalence of $21.6 \%$ [2]; and the prevalence is $21 \%$ in New Zealand [3], and 23\% in Australia [4] among reproductive-aged women. The prevalence of PCOS in South Asian women, especially in Pakistani women, is much higher (52\%) as compared to the white population (20-25\% in the UK) [5].

PCOS was initially described by Stein and Leventhal in 1935, although it had a history of at least a century beforehand [6]. Stein and Leventhal initially defined this disorder with enlarged ovaries, hirsutism, obesity, and anovulation. Rotterdam criteria described PCOS as a disorder with at least two of the clinical features: i) oligo- or anovulation, ii) clinical or biochemical signs of hyperandrogenism, and iii) polycystic ovaries, with the exclusion of other etiologies (congenital adrenal hyperplasia, androgen, secreting tumors, Cushing's syndrome) [7]. 
Women with PCOS can be classified into four potential phenotypes based on history, physical examination, and investigations [8]: i) PCOS complete, which is oligo-/anovulation (0) + polycystic ovaries $(P)$ + hyperandrogenism $(\mathrm{H})$, ii) polycystic ovaries + oligo-/anovulation, iii) polycystic ovaries + hyperandrogenism, and iv) oligo-/anovulation + hyperandrogenism [9].

Establishing a diagnosis of PCOS is difficult among adolescents and menopausal women [10]. The features of PCOS begin at menarche, but appear after puberty. Several hormonal factors are responsible for promoting such risk factors, especially including high levels of gonadotropin-releasing hormone $(\mathrm{GnRH})$, follicle-stimulating hormone (FSH), luteinizing hormone (LH), insulin, androgen, Anti-Müllerian hormone $(\mathrm{AMH})$, vitamin $\mathrm{D}$ deficiency, and calcitonin.

The LH level is often two to three times that of the FSH level. It is typical for women with PCOS to have an LH level of about $18 \mathrm{IU} / \mathrm{mL}$ and an FSH of $6 \mathrm{IU} / \mathrm{mL}$. LH hypersecretion, both basally and in response to $\mathrm{GnRH}$, is a characteristic hallmark of PCOS and can be recognized as the primary abnormality in classic PCOS causing androgen excess [11].

Women with PCOS were found to have higher serum AMH due to a greater number of antral follicles and increased production of $\mathrm{AMH}$ per follicle. There is limited evidence to define the cutoff value for $\mathrm{AMH}$ as a diagnostic tool for PCOS. Some studies have recommended that an AMH level greater than $3.8-5 \mathrm{ng} / \mathrm{mL}$ can be used as a diagnostic factor for PCOS [12] and suggested using Rotterdam criteria and AMH level concurrently for early and accurate diagnosis. The presence of two out of three clinical features (OA, HA, and $\mathrm{AMH}$ ) was found to have $96 \%$ sensitivity and $100 \%$ specificity among patients previously diagnosed with PCOS according to the Rotterdam criterion [13].

The diagnosis of PCOS among the reproductive age group using AMH level has been studied in many populations, but evidence from Pakistan is missing on AMH level association with PCOS. Therefore, this study aims to analyze serum AMH levels as a predictor of PCOS among women of the reproductive age group. This study will help to understand the pattern and utilization of serum AMH level as a diagnostic factor among PCOS women.

\section{Materials And Methods}

\section{Study design and setting}

A cross-sectional study design was used to measure the reproductive characteristics and hormonal levels among PCOS women. This study is a part of the doctoral thesis project of the first author (MSB). Data were collected during June 2019 to April 2020 from the outdoor fertility center of a private hospital in Lahore, Pakistan. Consultant gynecologists (authors SA and IS) examined the participants to be recruited in the study.

\section{Study population}


The inclusion criteria for this study were women aged 15-45 years, with both ovaries intact, and newly diagnosed with PCOS by the consultant gynecologists following a transvaginal pelvic ultrasound (Toshiba Xario Prime, Crawley, UK) investigation for PCOS confirmation and measuring ovary volume. According to Rotterdam criteria, antral follicle count on ultrasound is related to polycystic ovarian morphology (PCOM). Modern technology has improved the follicle detections on ultra-sonography, but still it requires specific equipment [14]. PCOM is diagnosed at appearance of $\geq 12$ follicles located on the periphery of the central stroma or at an ovarian volume $>10 \mathrm{~cm}^{3}[15]$.

All participants were in good health and were not taking any medication known to affect sex hormones or metabolism three months before participating in the study. Women with moderate to severe endometriosis, previous history of surgery, and preexisting diabetes mellitus before the diagnosis of PCOS were excluded from the study after being clinically assessed by experienced physicians.

\section{Sampling technique}

A purposive sampling technique was used to collect data. A total of 98 newly diagnosed women with PCOS were screened for participation in this study. Data were obtained from 51 PCOS-diagnosed women aged 28.24 years ( $S D \pm 4.84$ years) meeting at least two of the Rotterdam criteria and specific inclusion criteria. Women with any comorbidity and previous history of surgery were excluded from the study.

\section{Data collection}

The consultant gynecologists clinically assessed the participants and recorded detailed menstrual cycle history and reproductive hormonal analysis. Study participants were categorized into normal and oligo-/amenorrhea groups based on their menstrual cycle history for statistical analysis. The normal menstrual cycle was defined as women with regular cycles from 22-30 days with an estimated average of 28 days. Women with menstrual cycle intervals $\geq 35$ days (4-8 periods per year) were grouped into oligo-/amenorrhea.

Baseline information on age, marriage duration, fertility status, menstrual cycle length, and previous history of treatment was measured using a demographic questionnaire after verbal consent of the participants. The weight of participants was measured in standing on a digital weighing scale (Beurer BF 600 ) with normal clothing, without shoes, and was rounded to the nearest 100 grams.

Clinical signs of hirsutism were assessed by Modified Ferriman-Gallwey (MFG) scale and a score greater than 8 is defined as hyperandrogenism [16]. Based on the MFG score, the hyperandrogenism was categorized into normal $(<8)$, mild $(8-15)$, moderate $(16-25)$, and severe $(>25)$. The biochemical evaluation was included serum follicle-stimulating hormone $(\mathrm{FSH}, \mathrm{mlU} / \mathrm{ml})$, luteinizing hormone $(\mathrm{LH}$, $\mathrm{IU} / \mathrm{L})$, prolactin $(\mathrm{ng} / \mathrm{ml})$, Anti-Müllerian hormone $(\mathrm{AMH}, \mathrm{ng} / \mathrm{ml})$, and thyroid-stimulating hormone (TSH, $\mathrm{IU} / \mathrm{L}$ ) during the follicular phase (1-5 days) of the menstrual cycle. Serum $\mathrm{LH}, \mathrm{FSH}$, and prolactin were measured using automated chemiluminescent immunoassays (Abbott Diagnostics, Maidenhead, UK). Serum AMH was measured by enzyme-linked immunosorbent assay (ELISA) according to the manufacturer's instructions (DRG® AMH ELISA, EIA-5738). 


\section{Data analysis}

The data were analyzed using the IBM SPSS version 23.0 and GraphPad Prism version 9. The demographic and reproductive characteristics are presented in absolute and relative values, as well as in mean (M) and standard deviation (SD). An independent T-test was used to compare the mean differences of the reproductive hormones between the women with the normal menstrual cycle and oligo-/amenorrhea. Reproductive characteristics of the PCOS women were compared using the independent T-test between the groups with normal $(\leq 3.9 \mathrm{ng} / \mathrm{ml})$ and high AMH $(>3.9 \mathrm{ng} / \mathrm{ml})$ levels. A linear regression model was used to predict the relationship between $\mathrm{AMH}$ levels and reproductive characteristics of the PCOS women.

\section{Ethical considerations}

This study was approved by the University of the Punjab research and Advanced Studies Board (ASRB) (ref \# D-6067-ACAD) and the Institutional Review Board (IRB) for ethical considerations (ref \# D/2022/UZ). All recruited participants provided informed consent before inclusion in the study following the guidelines of the Declaration of Helsinki [17].

\section{Results}

A total of 51 women with a mean age of 28.24 years $(S D \pm 4.84)$ and married for 4.62 years $(S D \pm 3.58)$ participated in this study. Mild (43.1\%), moderate (35.3\%), and severe hirsutism (11.8\%) were recorded among the PCOS women representing the clinical signs of hyperandrogenism. Participants had menstrual cycle irregularities (39.29 \pm 25.35 days) with oligo-/amenorrhea $(64.7 \%)$ pattern. Polycystic ovarian morphology (PCOM, Vol $>10 \mathrm{~cm}^{3}$ ) was evident among PCOS women for both ovaries (Table 1). 
Table 1

Demographic and reproductive characteristics of PCOS women

\begin{tabular}{|c|c|c|}
\hline Variables & Groups & $\mathrm{n}(\%)$ \\
\hline \multirow{3}{*}{$\begin{array}{l}\text { Age group (years) } \\
28.24(4.84) *\end{array}$} & $15-25$ & $16(31.4)$ \\
\hline & $26-35$ & $32(62.7)$ \\
\hline & $36-45$ & $3(5.9)$ \\
\hline \multirow{3}{*}{$\begin{array}{l}\text { Marriage duration (years) } \\
4.62(3.58) *\end{array}$} & $<1$ & $6(11.8)$ \\
\hline & $1-5$ & $32(62.7)$ \\
\hline & $>5$ & $13(25.5)$ \\
\hline \multirow[t]{2}{*}{ Fertility status } & Primary & $40(78.4)$ \\
\hline & Secondary & $11(21.6)$ \\
\hline \multirow[t]{3}{*}{ Past treatment } & None & $10(19.6)$ \\
\hline & Ovarian induction & $31(60.8)$ \\
\hline & Multiple & $10(19.6)$ \\
\hline \multirow{3}{*}{$\begin{array}{l}\text { Weight }(\mathrm{kg}) \\
75.22(13.71) \text { * }\end{array}$} & $55-75$ & $31(60.8)$ \\
\hline & $76-95$ & $16(31.4)$ \\
\hline & $96-115$ & $4(7.8)$ \\
\hline \multirow[t]{4}{*}{ Hirsutism (MFG score) } & None $(\leq 7)$ & $5(9.8)$ \\
\hline & Mild (8-15) & $22(43.1)$ \\
\hline & Moderate (16-25) & 18 (35.3) \\
\hline & Severe $(26-34)$ & $6(11.8)$ \\
\hline \multirow{3}{*}{$\begin{array}{l}\text { Menstrual cycle length } \\
39.29 \text { (25.35) (days) }\end{array}$} & Normal & 18 (35.3) \\
\hline & Oligomenorrhea & $18(35.3)$ \\
\hline & Amenorrhea & $15(29.4)$ \\
\hline \multirow[t]{2}{*}{ Left ovary volume } & Without PCOM $\left(\mathrm{Vol}<10 \mathrm{~cm}^{3}\right)$ & $5(9.8)$ \\
\hline & $\operatorname{PCOM}\left(\right.$ Vol $\left.>10 \mathrm{~cm}^{3}\right)$ & $46(90.2)$ \\
\hline \multirow[t]{2}{*}{ Right ovary volume } & Without PCOM $\left(\mathrm{Vol}<10 \mathrm{~cm}^{3}\right)$ & $8(15.7)$ \\
\hline & $\operatorname{PCOM}\left(\right.$ Vol > $\left.10 \mathrm{~cm}^{3}\right)$ & $43(84.3)$ \\
\hline *Mean (SD) & & \\
\hline
\end{tabular}


PCOS women $(70.6 \%)$ showed high AMH $(>3.90 \mathrm{ng} / \mathrm{ml})$ levels when measured for reproductive hormonal level in the serum. FSH $(<9 \mathrm{mlU} / \mathrm{ml}), \mathrm{LH}(<12.5 \mathrm{IU} / \mathrm{L})$, prolactin $(<29 \mathrm{ng} / \mathrm{ml})$, and TSH $(<4.0 \mathrm{mmlU} / \mathrm{L})$ were found normal among the majority of the participants (Table 2).

Table 2

Reproductive hormone levels among PCOS women

\begin{tabular}{|c|c|c|c|}
\hline Variable & Groups & $n(\%)$ & Mean (SD) \\
\hline \multirow{2}{*}{$\begin{array}{l}\text { Follicle Stimulating Hormone } \\
\text { (FSH) }\end{array}$} & Normal $(\leq 9 \mathrm{mlU} / \mathrm{ml})$ & $49(96.1)$ & \multirow[t]{2}{*}{$5.63(1.79)$} \\
\hline & High $(\geq 9 \mathrm{mlU} / \mathrm{ml})$ & $7(15.7)$ & \\
\hline \multirow{2}{*}{$\begin{array}{l}\text { Luteinizing Hormone } \\
\text { (LH) }\end{array}$} & Normal ( $\leq 12.5 \mathrm{IU} / \mathrm{L})$ & $43(84.3)$ & \multirow[t]{2}{*}{$8.58(5.45)$} \\
\hline & $\operatorname{High}(\geq 12.5 \mathrm{IU} / \mathrm{L})$ & $8(15.7)$ & \\
\hline \multirow[t]{2}{*}{ Prolactin } & Normal $(\leq 29 \mathrm{ng} / \mathrm{ml})$ & $45(88.2)$ & \multirow[t]{2}{*}{$16.68(13.71)$} \\
\hline & High ( $\geq 29$ ng/ml) & $6(11.8)$ & \\
\hline \multirow[t]{2}{*}{ Anti-Müllerian hormone (AMH) } & Normal $(\leq 3.9 \mathrm{ng} / \mathrm{ml})$ & $15(29.4)$ & \multirow[t]{2}{*}{$7.23(4.67)$} \\
\hline & High $(\geq 3.9 \mathrm{ng} / \mathrm{ml})$ & $36(70.6)$ & \\
\hline \multirow[t]{2}{*}{ Thyroid Stimulating Hormone (TSH) } & Normal ( $\leq 4.0 \mathrm{mmlU} / \mathrm{L})$ & $50(98.0)$ & \multirow[t]{2}{*}{$1.94(0.82)$} \\
\hline & $\operatorname{High}(\geq 4.0 \mathrm{mmlU} / \mathrm{L})$ & $1(2.0)$ & \\
\hline
\end{tabular}

Independent T-test showed a significant mean difference $(\mathrm{p}<0.05)$ for $\mathrm{AMH}$ and $\mathrm{LH}$ reproductive hormones when compared between normal and oligo-/amenorrhea menstrual patterns (Table 3). Mean group comparison between PCOS women with normal and high AMH levels showed a significant relationship $(p<0.05)$ with left ovary volume and LH hormone. PCOM among women can be used as an important clinical feature to diagnose PCOS. Based on previous studies' evidence, a threshold of 3.9 $\mathrm{ng} / \mathrm{mL}$ was considered normal in the present study to make a group comparison of PCOS women with higher AMH levels (Table 4). PCOS women (70.6\%) showed a higher AMH level ( $\geq 3.9 \mathrm{ng} / \mathrm{ml}$ ). 
Table 3

Comparison of reproductive hormone levels between normal and oligo-/ amenorrhea group

\begin{tabular}{|c|c|c|c|}
\hline \multirow[t]{2}{*}{ Reproductive Hormone } & \multicolumn{2}{|c|}{ PCOS Women Menstrual Cycle Length } & \multirow{2}{*}{$\begin{array}{l}\text { Mean difference }{ }^{a} \\
(95 \% \mathrm{Cl})\end{array}$} \\
\hline & $\begin{array}{l}\text { Normal } \\
(\text { Mean } \pm \text { SD })\end{array}$ & $\begin{array}{l}\text { Oligo/Amenorrhea } \\
\text { (Mean } \pm \text { SD) }\end{array}$ & \\
\hline Follicle Stimulating Hormone (FSH) & $5.52 \pm 1.78$ & $5.69 \pm 1.82$ & $0.75(-1.23,0.89)$ \\
\hline Luteinizing Hormone (LH) & $6.67 \pm 2.46$ & $9.62 \pm 6.33$ & $0.02 *(-5.46,-0.44)$ \\
\hline Prolactin & $19.85 \pm 20.40$ & $14.96 \pm 8.01$ & $0.34(-5.55,15.34)$ \\
\hline Anti-Müllerian hormone (AMH) & $5.34 \pm 3.19$ & $8.27 \pm 5.05$ & $0.03 *(-5.57,-0.28)$ \\
\hline Thyroid Stimulating Hormone (TSH) & $1.97 \pm 0.92$ & $1.94 \pm 0.77$ & $0.90(-0.45,0.52)$ \\
\hline
\end{tabular}

Table 4

Comparison of reproductive characteristics between normal and high AMH levels among PCOS women

\begin{tabular}{|c|c|c|c|}
\hline \multirow{3}{*}{$\begin{array}{l}\text { Reproductive } \\
\text { outcome measure }\end{array}$} & \multicolumn{2}{|c|}{ Anti-Müllerian hormone level among PCOS women } & \multirow{3}{*}{$\begin{array}{l}\begin{array}{l}\text { Mean } \\
\text { difference }^{a} \\
(95 \% \mathrm{Cl})\end{array}\end{array}$} \\
\hline & $\begin{array}{l}\text { Normal (Less than } 3.9 \\
\mathrm{ng} / \mathrm{ml} \text { ) }\end{array}$ & $\begin{array}{l}\text { High (Greater than } 3.9 \\
\mathrm{ng} / \mathrm{ml} \text { ) }\end{array}$ & \\
\hline & $($ Mean \pm SD) & (Mean \pm SD) & \\
\hline Age & $29.67 \pm 5.32$ & $27.93 \pm 4.74$ & $\begin{array}{l}0.38(-1.83 \\
5.31)\end{array}$ \\
\hline $\begin{array}{l}\text { Average menstrual cycle } \\
\text { days }\end{array}$ & $30.33 \pm 15.51$ & $41.21 \pm 26.33$ & $\begin{array}{l}0.25(-29.52 \\
7.76)\end{array}$ \\
\hline Left ovary volume & $18.40 \pm 6.36$ & $14.91 \pm 4.30$ & $\begin{array}{l}0.05^{*}(0.02 \\
6.95)\end{array}$ \\
\hline Right ovary volume & $13.81 \pm 5.72$ & $14.36 \pm 3.61$ & $\begin{array}{l}0.71(-3.53 \\
2.42)\end{array}$ \\
\hline $\begin{array}{l}\text { Follicle Stimulating Hormone } \\
\text { (FSH) }\end{array}$ & $5.82 \pm 1.96$ & $5.58 \pm 1.77$ & $\begin{array}{l}0.73(-1.10 \\
1.56)\end{array}$ \\
\hline Luteinizing Hormone (LH) & $5.63 \pm 1.43$ & $9.21 \pm 5.78$ & $\begin{array}{l}0.01 *(-7.52, \\
0.35)\end{array}$ \\
\hline Prolactin & $15.30 \pm 11.05$ & $16.98 \pm 14.31$ & $\begin{array}{l}0.73(-11.88 \\
8.54)\end{array}$ \\
\hline $\begin{array}{l}\text { Thyroid Stimulating } \\
\text { Hormone (TSH) }\end{array}$ & $2.26 \pm 0.82$ & $1.87 \pm 0.80$ & $\begin{array}{l}0.20(-0.21 \\
0.98)\end{array}$ \\
\hline
\end{tabular}


A linear regression model was used to predict the pattern of $\mathrm{AMH}$ with various reproductive characteristics and serum levels of hormones as shown in Figs. 1 and 2. The slope of the regression line showed a significant decline in serum AMH level with an increase in age. AMH level tends to increase with weight, menstrual abnormalities, and hirsutism. LH was the only reproductive hormone that increases with the elevation of serum AMH levels among PCOS women.

\section{Discussion}

Our study found that PCOS women had an increased menstrual cycle length with the elevation in serum AMH level and had a greater risk of menstrual disturbance. The increase in menstrual cycle length with AMH elevation was concurrent with previous studies [18]. Serum AMH is highly correlated to the antral follicle count, which acts as a biomarker for an ovarian response [19]. Serum AMH level can be a predictive tool for oligo-/ amenorrhea with higher per antral secretion among PCOS women.

The results of this study found that the risk of oligo-/amenorrhea increases with higher serum AMH levels and it was difficult to define a single threshold value. A trend towards an increase in menstrual cycle length was obvious when compared with the increase in $\mathrm{AMH}$ level. A threshold of $\mathrm{AMH}$ level between $3.8-5 \mathrm{ng} / \mathrm{mL}$ has being reported previously to diagnose PCOS [12]. Serum AMH concentration in PCOS patients has also been reported high in previous studies when compared with $\mathrm{BMI}$ and aged-matched controls [20]. Being a quantitative laboratory parameter, serum AMH can be used for the assessment of ovarian reserve by taking a blood sample on any day of the cycle [21].

Serum AHM level also showed a significant relationship $(p=0.01)$ with $\mathrm{LH}$ and tends to increase LH secretion with higher AMH levels. LH predominant secretion among PCOS women also had a significant relationship $(p=0.02)$ with menstrual disturbance. Similar findings were reported in another study suggesting that the $\mathrm{GnRH}$ made LH-predominance in the follicular phase commensurate with higher AMH levels and menstrual disturbance [22].

The abnormalities of increased LH secretion have been reported among PCOS women $>40$ years as a result of accelerated $\mathrm{GnRH} / \mathrm{LH}$ pulsatility. The FSH levels were found to remain normal resulting in increased LH/FSH ratio during the follicular phase of the menstrual cycle among PCOS women [23]. The $\mathrm{LH} / \mathrm{FSH}$ ratio depends on the assay used to measure these gonadotropins makes it difficult to define a cutoff value and its application in clinical settings [24]. For these reasons, the gonadotropin measurements are not evident for the PCOS diagnosis.

Hyperandrogenism is one of the Rotterdam criteria to diagnose PCOS and is prominent among PCOS women with increased BMI. PCOS women with high follicle counts and increased BMI levels were prone to biochemical hyperandrogenism [22]. Clinical features of hyperandrogenism have frequently been seen among PCOS women which include hirsutism, acne, and androgenic alopecia [24]. Hirsutism is one of the auspicious features of hyperandrogenism and was found prevalent among our study participants. 
A positive correlation between serum AMH level and androgen has previously been reported. Hyperandrogenism has been reported as an intrinsic defect of thecal cells in PCOS women and is positively associated with testosterone levels and ovarian volume [25]. The clinical symptoms of hirsutism and menstrual cycle abnormality have also been reported high in our study. A trend of increase in body weight and hirsutism was observed when compared with elevation in serum AMH levels.

In our data, PCOM in both ovaries was present in the majority of participants. The PCOS women had PCOM, hyperandrogenism, and oligo-/amenorrhea along with raised serum AMH levels. The findings of this study suggest that $\mathrm{AMH}$ can be used as a biochemical marker to reliably identify PCOS based on the clinical features defined by the Rotterdam criteria. The combination of $\mathrm{AMH}$ with Rotterdam criteria can better identify PCOS. Teede et al. [26] summarized the potential challenges to use serum AMH level to diagnose PCOS which needs to be incorporated for effective use of this diagnostic tool.

PCOS remains a syndrome and as such no single diagnostic criteria are sufficient for clinical diagnosis. Environmental factors have also been reported to play an essential role in PCOS pathogenesis [27] which is beyond the scope of our research. Similarly, genetics also play a momentous role in the origin of this disease [28]. The phenotypic presentation of PCOS women can be altered with baseline variables such as age, BMI, physical activity level, and dietary patterns which limited the findings of this study. The potential limitation of our data includes a small sample size and purposive sampling of women visiting the outdoor fertility center. This study did not compare the serum AMH levels with age and BMI-matched non-PCOS women to estimate the normal ranges and trends. Considering the cross-sectional nature of the study, the participants were not observed over a longer period with follow-up biochemical analysis of serum $\mathrm{AMH}$ and other reproductive hormones to make an intra-rater comparison.

Strengths of this study include that specialist gynecologists screened the newly diagnosed PCOS women and had the expertise of accurate assessment of ovarian morphology on ultrasound along with other PCOS features resulted in reduced inter-and intra-observer bias. This study addresses an unattended research area in Pakistan and highlights the importance of $\mathrm{AMH}$ in the accurate diagnosis of PCOS. Future research with broader baseline variables, comparison with healthy controls, and studying PCOS women cohorts for a longer period could yield further interesting findings in utilizing the serum AMH level as a diagnostic tool for PCOS.

\section{Conclusions}

Serum AMH level can be used as a strong predictor for disturbance in reproductive characteristics such as menstrual cycle disturbance, PCOM, and clinical signs of hyperandrogenism. An elevated serum AMH level could reflect the certainty of PCOS diagnosis among women of reproductive age with a greater number of PCOS features.

\section{Abbreviations}


$\mathrm{AMH}$

Anti-Müllerian hormone

ELISA

Enzyme-linked immunosorbent assay

FSH

Follicle-stimulating hormone

$\mathrm{GnRH}$

Gonadotropin-releasing hormone

$\mathrm{LH}$

Luteinizing hormone

M

Mean

MFG

Modified Ferriman-Gallwey

PCOM

Polycystic ovarian morphology

PCOS

Polycystic ovarian syndrome

SD

Standard deviation

TSH

Thyroid-stimulating hormone

\section{Declarations}

\section{Ethics approval and consent to participate:}

This study was approved by the University of the Punjab research and Advanced Studies Board (ASRB) (ref \# D-6067-ACAD) and the Institutional Review Board (IRB) for ethical considerations (ref \# D/2022/UZ). All methods were performed in accordance with the Declaration of Helsinki. The study participants provided informed consent before inclusion in the study.

\section{Consent for publication:}

Not applicable.

\section{Availability of data and materials:}

The dataset generated and analysed during the current study is not publicly available, because participants consent only referred to a publication of aggregated data. However, the dataset can be made available from the corresponding author on reasonable request. 


\section{Competing interest:}

The authors declare that they have no competing interests.

\section{Funding:}

None

\section{Authors' contributions:}

Conceptualization: M.S.B. and R.Z.; formal analysis: M.S.B.; investigation: M.S.B, S.A. and I.S.; supervision: F.F.; writing-original draft preparation: M.S.B.; writing-review and editing: J.S., S.A., R.Z., I.S. and F.F. All authors have read and agreed to the published version of the manuscript.

\section{Acknowledgements:}

None

\section{References}

1. Michelmore KF, Balen AH, Dunger DB, Vessey MP. Polycystic ovaries and associated clinical and biochemical features in young women. Clin Endocrinol. 1999;51(6):779-86. doi: 10.1046/j.13652265.1999.00886.x

2. Koivunen R, Laatikainen T, Tomas C, Huhtaniemi I, Tapanainen J, Martikainen H. The prevalence of polycystic ovaries in healthy women. Acta Obstet Gynecol Scand. 1999;78(2):137-41.

3. Farquhar CM, Birdsall M, Manning P, Mitchell JM, France JT. The Prevalence of Polycystic Ovaries on Ultrasound Scanning in a Population of Randomly Selected Women. Aust New Zeal J Obstet Gynaecol. 1994;34(1):67-72. doi: 10.1111/j.1479-828x.1994.tb01041.x

4. Lowe P, Kovacs $G$, Howlett D. Incidence of polycystic ovaries and polycystic ovary syndrome amongst women in Melbourne, Australia. Aust New Zeal J Obstet Gynaecol. 2005;45(1):17-9. doi: 10.1111/j.1479-828X.2005.00334.x

5. Akram M, Roohi N. Endocrine correlates of polycystic ovary syndrome in Pakistani women. J Coll Physicians Surg Pakistan. 2015;25(1):22-6.

6. Stein IF, Leventhal ML. Amenorrhea is associated with bilateral polycystic ovaries. Am J Obstet Gynecol. 1935;29(2):181-91. doi: 10.1016/j.ajog.2015.12.013

7. Fauser BCJM. Revised 2003 consensus on diagnostic criteria and long-term health risks related to polycystic ovary syndrome. Fertil Steril. 2004;81(1):19-25. doi: 10.1016/j.fertnstert.2003.10.004

8. Sobti S, Dewan R, Ranga S. Metabolic syndrome and insulin resistance in PCOS phenotypes. Int J Reprod Contraception Obstet Gynecol. 2017;6(11):5067. doi: 10.18203/2320-1770.ijrcog20175027 
9. Kar S. Anthropometric, clinical, and metabolic comparisons of the four Rotterdam PCOS phenotypes: A prospective study of PCOS women. J Hum Reprod Sci. 2013;6(3):194-200. doi: 10.4103/09741208.121422

10. Legro RS, Arslanian SA, Ehrmann DA, Hoeger KM, Murad MH, Pasquali R et al. Diagnosis and treatment of polycystic ovary syndrome: An endocrine society clinical practice guideline. J Clin Endocrinol Metab. 2013;98(12):4565-92. doi: 10.1210/jc.2013-2350

11. Tsilchorozidou T, Overton C, Conway GS. The pathophysiology of polycystic ovary syndrome. Clinical Endocrinology. 2004;60:1-17. doi: 10.1046/j.1365-2265.2003.01842.x

12. Sahmay S, Aydin Y, Oncul M, Senturk LM. Diagnosis of polycystic ovary syndrome: AMH in combination with clinical symptoms. J Assist Reprod Genet. 2014;31(2):213-20. doi:

10.1007/s10815-013-0149-0

13. Dewailly D, Gronier H, Poncelet E, Robin G, Leroy M, Pigny P et al. Diagnosis of polycystic ovary syndrome (PCOS): Revisiting the threshold values of follicle count on ultrasound and of the serum AMH level for the definition of polycystic ovaries. Hum Reprod. 201;26(11):3123-29. doi:

10.1093/humrep/der297

14. Mohammad MB, Seghinsara AM. Polycystic ovary syndrome (PCOS), diagnostic criteria, and AMH. Asian Pacific J Cancer Prev. 2017;18(1):17-21. doi: 10.22034/APJCP.2017.18.1.17

15. Balen AH, Laven JSE, Tan SL, Dewailly D. Ultrasound assessment of the polycystic ovary: International consensus definitions. Hum Reprod Update. 2003;9(6):505-14. doi: 10.1093/humupd/dmg044

16. Hatch R, Rosenfield RL, Kim MH, Tredway D. Hirsutism: Implications, etiology, and management. Am J Obstet Gynecol. 1981;140(7):815-30. doi: 10.1016/0002-9378(81)90746-8

17. World Medical Association. World Medical Association Declaration of Helsinki: Ethical principles for medical research involving human subjects. J Am Coll Dent. 2014;81(3):14-8.

18. Zhu R, Lee BH, Huang Z, Indran IR, Li J, Shen L et al. Antimüllerian hormone, antral follicle count and ovarian volume predict menstrual cycle length in healthy women. Clin Endocrinol. 2016;84(6):870-7. doi: $10.1111 /$ cen.12984

19. Nyboe Andersen A, Nelson SM, Fauser BCJM, García-Velasco JA, Klein BM, Arce JC et al. Individualized versus conventional ovarian stimulation for in vitro fertilization: a multicenter, randomized, controlled, assessor-blinded, phase 3 noninferiority trial. Fertil Steril. 2017;107(2):38796. doi: 10.1016/j.fertnstert.2016.10.033

20. Sova H, Unkila-Kallio L, Tiitinen A, Hippeläinen M, Perheentupa A, Tinkanen $\mathrm{H}$ et al. Hormone profiling, including anti-Müllerian hormone $(\mathrm{AMH})$, for the diagnosis of polycystic ovary syndrome (PCOS) and characterization of PCOS phenotypes. Gynecol Endocrinol. 2019;35(7):595-600. doi: 10.1080/09513590.2018.1559807

21. Van Disseldorp J, Lambalk CB, Kwee J, Looman CWN, Eijkemans MJC, Fauser BC et al. Comparison of inter- and intra-cycle variability of anti-Müllerian hormone and antral follicle counts. Hum Reprod. 2010;25(1):221-7. doi: 10.1093/humrep/dep366 
22. Abbara A, Eng PC, Phylactou M, Clarke SA, Hunjan T, Roberts R et al. Anti-müllerian hormone (AMH) in the diagnosis of menstrual disturbance due to polycystic ovarian syndrome. Front Endocrinol. 2019;10:656. doi: 10.3389/fendo.2019.00656

23. Noweir MH, Bafail AO. Study of summer heat exposure at the ground services operations of a main international airport in Saudi Arabia. Environ Monit Assess. 2008;145(1-3):103-11. doi: 10.1007/s10661-007-0019-2

24. Azziz R, Carmina E, Dewailly D, Diamanti-Kandarakis E, Escobar-Morreale HF, Futterweit W et al. The Androgen Excess and PCOS Society criteria for the polycystic ovary syndrome: the complete task force report. Fertil Steril. 2009;91(2):456-88. doi: 10.1016/j.fertnstert.2008.06.035

25. Carlsen SM, Vanky E, Fleming R. Anti-Müllerian hormone concentrations in androgen-suppressed women with polycystic ovary syndrome. Hum Reprod. 2009;24(7):1732-8. doi:

10.1093/humrep/dep074

26. Teede H, Misso M, Tassone EC, Dewailly D, Ng EH, Azziz R et al. Anti-Müllerian Hormone in PCOS: A Review Informing International Guidelines. Trends Endocrinol Metab. 2019;30(7):467-8. doi: 10.1016/j.tem.2019.04.006

27. Barthelmess, E.K., Naz, R.K. Polycystic ovary syndrome: Current status and future perspective. Front. Biosci. 6(1), 104-119 (2014). https://doi.org/10.2741/e695

28. Chen ZJ, Zhao H, He L, Shi Y, Qin Y, Shi Y et al. Genome-wide association study identifies susceptibility loci for polycystic ovary syndrome on chromosome 2p16.3, $2 p 21$ and 9q33.3. Nat Genet. 2011;43(1):55-9. doi: 10.1038/ng.732

\section{Figures}


$\mathrm{AMH}$ and Age
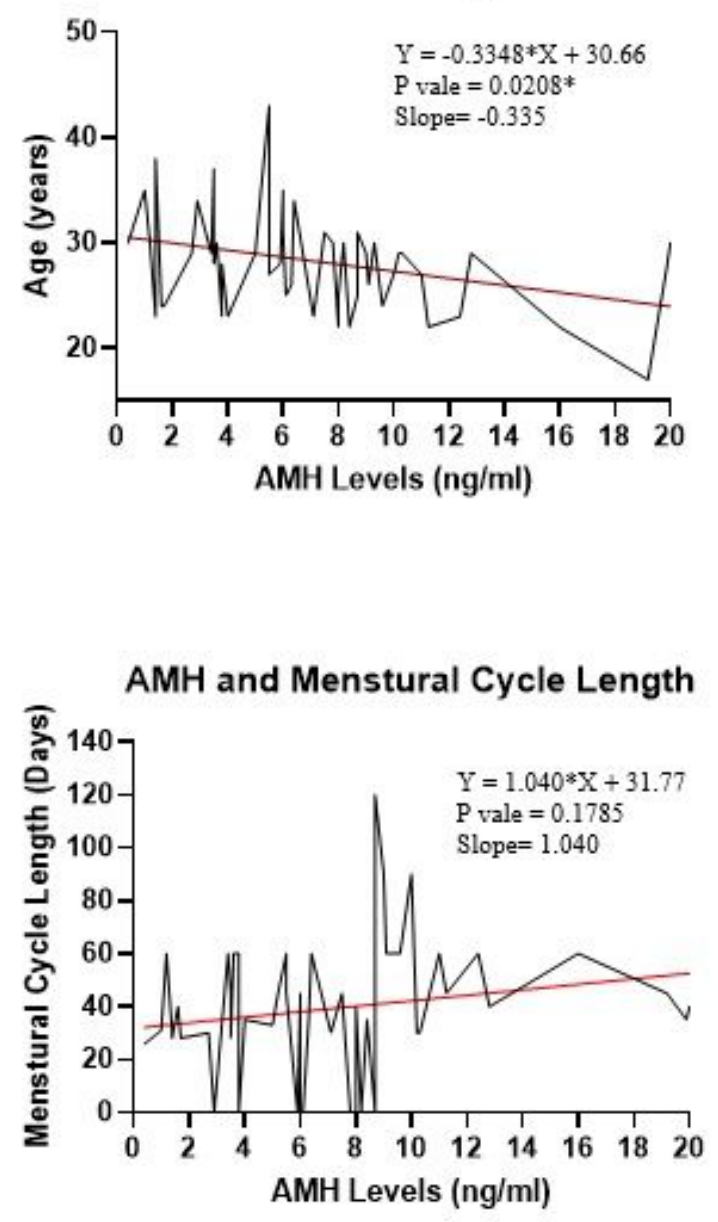

AMH and Ova Volume (Left)

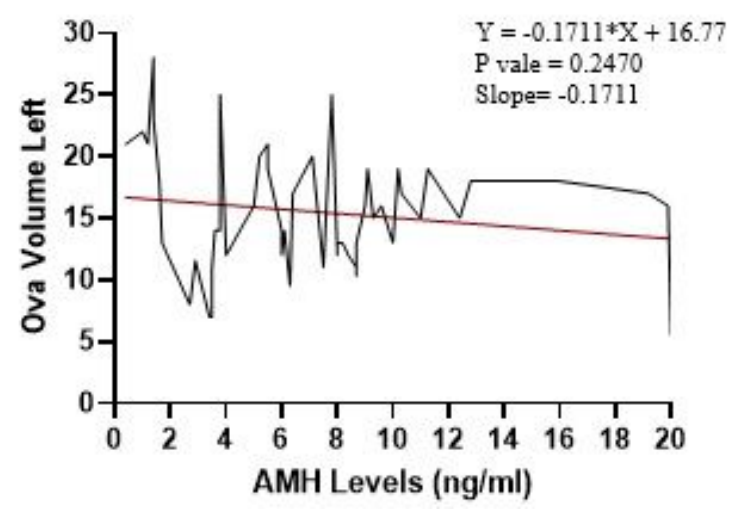

$\mathrm{AMH}$ and Weight

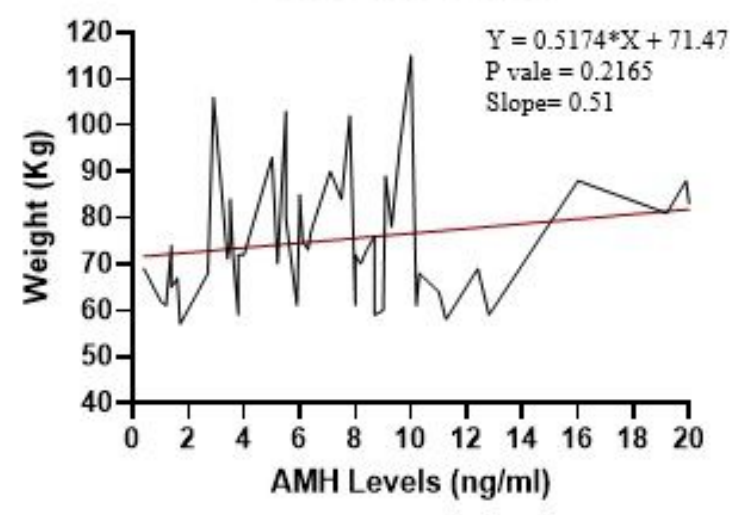

AMH and F-G Score (Hirsutism)

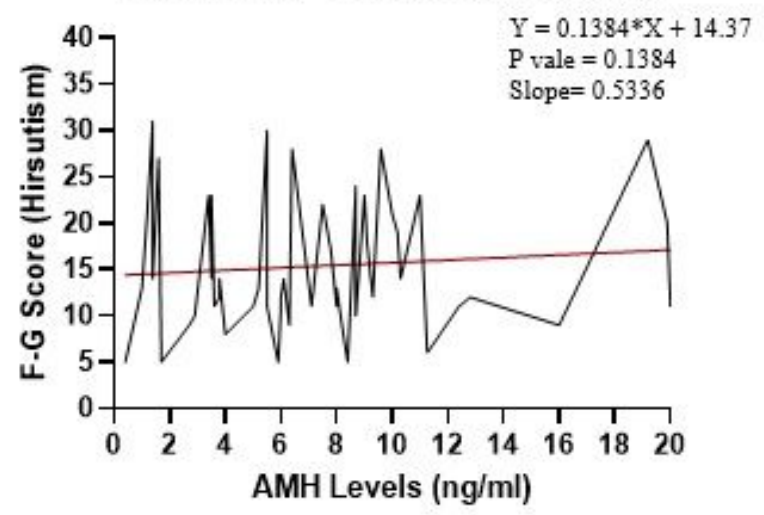

AMH and Ova Volume (Right Ovary)

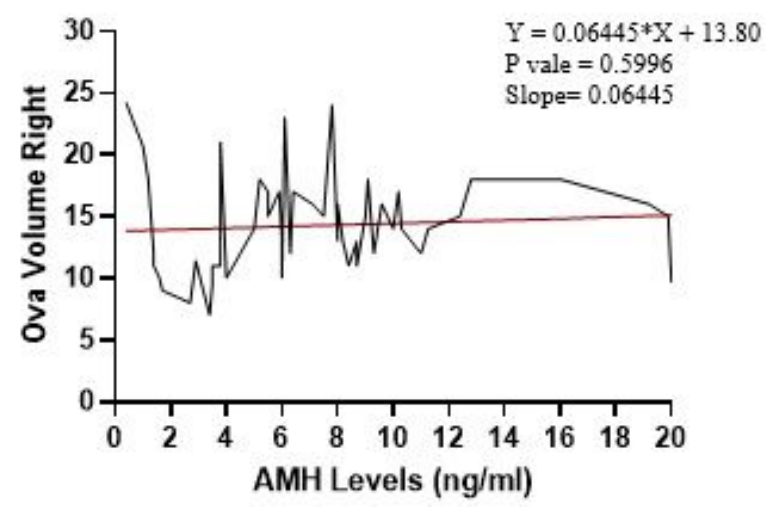

Figure 1

Linear regression model for AMH levels and PCOS women characteristics

Figure 2 
Linear regression model for $\mathrm{AMH}$ and reproductive hormonal levels among PCOS women 